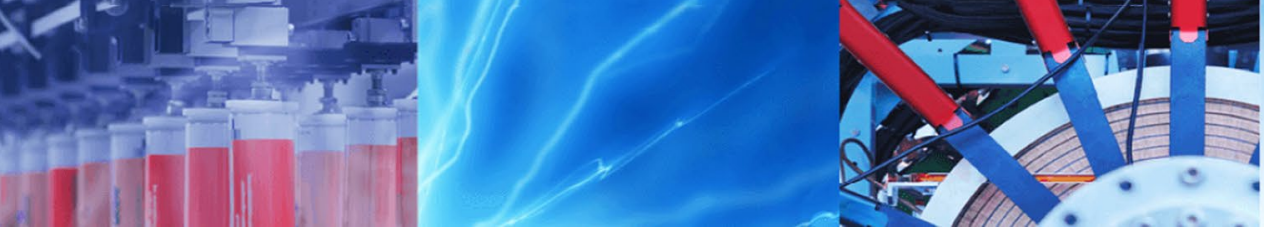

Research Article

\title{
Chemical doping of $\mathrm{TiO}_{2}$ Nano-tube array for enhancing hydrogen production through photoelectrochemical water splitting
}

\author{
Mehdi Farahmand ${ }^{1} \cdot$ Ali Allahverdi ${ }^{1}$ (1)
}

Received: 24 March 2020 / Accepted: 21 August 2020 / Published online: 31 August 2020

(c) Springer Nature Switzerland AG 2020

\begin{abstract}
Nano-tube array is one of the most important types of titanium dioxide-based nanostructures that attracted researchers' attention because of its superior photocatalytic properties. In this research, a thin layer of a titanium dioxide nano-tube array was first prepared by a two-step electrochemical anodizing process by using a titanium sheet. The synthesized nano-tube array was then calcined to obtain a good crystalline structure for enhanced photocatalytic properties. The length, diameter, and thickness of the nano-tubes were measured using SEM imaging technique. In order to enhance the photocatalytic properties, the synthesized nano-tube array was then doped individually with three different chemicals including silver nitrate, potassium ferricyanide and copper sulfate using the chemical bath deposition technique. The photocatalytic properties of the synthesized nano-tube array and the doped samples were evaluated and compared by photoelectrochemical water splitting. The results show that the nano-tube array doped with copper sulfate increases the rate of hydrogen production by up to three times producing as much as $21.65 \mathrm{mmol}$ after $5 \mathrm{~h}$.
\end{abstract}

Keywords Titanium dioxide · Nano-tube array · Anodization · Photoelectrochemical water splitting

\section{Introduction}

Hydrogen is an ideal, renewable and clean fuel that burns out and produces energy and water, and is likely to be a good alternative to fossil fuels due to the possibility of eliminating carbon emission [1, 2]. An environmentally friendly method of hydrogen production is photocatalytic water. Photocatalysts are semiconductors that are capable of creating electron-hole pairs upon absorbing light photons of sufficient energy. The energy absorbed from light photons results in the excitement of electrons generally filling the outermost shell of the atom (valence state) into higher energy orbitals (conduction state) that are generally empty $[3,4]$. The produced electron-hole pairs are then capable of carrying out redox reactions including the water-splitting reaction to produce hydrogen and oxygen [5]. In 1972, titanium dioxide $\left(\mathrm{TiO}_{2}\right)$ was the first catalyst used by Fujishima and Honda as photoanode in photoelectrochemical cells (PECs) for water splitting and hydrogen production [6]. In 2001, Grimes et al. [7] synthesized titanium dioxide nano-tubes array (TDNA) that attracted scientists' attention due to its highly ordered structure, very high surface area, and chemical stability. Titanium dioxide is excited only by UV light because of its relatively large energy band gap of $3.2 \mathrm{eV}$ [7]. In order to reduce its energy band gap and increase the hydrogen production rate, attempts have been devoted to dope TDNA with various elements [8]. In addition, different techniques including chemical vapor deposition (CVD), physical vapor deposition (PVD), sputtering, and chemical bath doping (CBD) have been developed and used to dope TDNA [9]. Among all the applied techniques, CBD is not only very low cost and simply applicable, but also it has scalability potential for commercial applications. Therefore, in this research,

Ali Allahverdi, ali.allahverdi@iust.ac.ir| ${ }^{1}$ Research Laboratory of Inorganic Chemical Process Technologies, School of Chemical Engineering, Iran University of Science and Technology, Narmak, 1684613114 Tehran, Iran. 
CBD was used as an appropriate and simple technique to dope TDNA with Ag, $\mathrm{Fe}$, and Cu using silver nitrate, potassium ferricyanide, and copper sulfate, respectively and to investigate the effect of doping on hydrogen production rate through photoelectrochemical water splitting.

In recent years, scientists have been able to increase the hydrogen production rate through photocatalytic and photoelectrochemical water splitting by applying the CBD technique [8-10]. In some of these investigations, according to the published data, doping with gold clusters increased the hydrogen production rate by approximately 3.4 times [10], doping with cadmium sulfide increased the hydrogen production by almost 5 times [9], doping with chromium increased the hydrogen production by about 13 times [11]. The doping technique has also been applied on TDNA by researchers. According to Lian et al. [12], In a different work, TDNA doping with carbon and nitrogen was able to increase the photoelectrochemical water splitting rate by 3.2 times with a bias voltage of $1 \mathrm{~V}$ [13]. It is also reported that cadmium sulfide and iron (III) oxide can improve the photoelectrochemical water splitting by 5 times [14]. Doping TDNA with tungsten trioxide was also investigated, but a relatively lower increase (by about 2.23 times) in hydrogen production rate [15]. Doping with zinc oxide was claimed to be more effective and increased the hydrogen production rate by almost 6.77 times [16]. Doping of TDNA with silver nano-particles after an annealing operation was able to increase the photoelectrochemical water splitting by 1.4 times at a bias voltage of $0.7 \mathrm{~V}$. In a different work, titanium tungstate nano-tubes synthesized by anodizing with a solution of dimethyl sulfoxide and hydrogen fluoride with sodium tungstate increased the photoelectrochemical water splitting rate by up to 2 times when doped with iron using CBD technique [17].

Many different elements have been doped onto titanium dioxide to enhance its photocatalytic properties, the most effective of which are $\mathrm{Pt}, \mathrm{Au}, \mathrm{Ag}, \mathrm{Pd}, \mathrm{Rh}, \mathrm{Ni}$, and $\mathrm{Cu}$ [18]. Silver and copper are among the elements that have a significant effect on the photocatalytic properties of titanium dioxide. $\mathrm{Fe}^{3+}$ also is very suitable for titanium dioxide doping and has the potential to participate in the crystalline structure of titanium dioxide due to its ionic radius $(0.64 \AA)$ compared to the ionic radius of and $\mathrm{Ti}^{4+}$ (0.68 A). These elements enhance the photocatalytic activity of titanium dioxide by reducing the recombination of electrons and holes [19]. For this reason, silver, copper, and iron have been considered as the most effective elements for titanium dioxide doping by many researchers.

In the present study, TDNA was first synthesized by the anodizing method and characterized by scanning electron microscopy (SEM) and X-ray diffractometry (XRD). The TDNA was then doped with silver, iron and copper using silver nitrate, potassium ferricyanide, and copper sulfate solution by applying CBD method at different times. Finally, the effect of doping on the hydrogen production by photoelectrochemical water splitting method was investigated and compared. The differences between the present work and previews similar works have been discussed in details in the "Results and discussion" section.

\section{Materials and methods}

\subsection{Materials}

In this research, the titanium sheet from Sigma-Aldrich company (99.7\% purity, $0.127-\mathrm{mm}$ thick), ethylene glycol $\left(\left(\mathrm{CH}_{2} \mathrm{OH}\right)_{2}, 99.5 \%\right.$ purity $)$, ammonium fluoride $\left(\mathrm{NH}_{4} \mathrm{~F}\right.$, 98\% purity), hydrogen fluoride ( $\mathrm{HF}, 48 \%$ purity), nitric acid $\left(\mathrm{HNO}_{3}, 65 \%\right.$ purity), sulfuric acid $\left(\mathrm{H}_{2} \mathrm{SO}_{4}, 96 \%\right.$ purity), sodium hydroxide ( $\mathrm{NaOH}, 97 \%$ purity), ammonium nitrate $\left(\mathrm{NH}_{4} \mathrm{NO}_{3}, 95 \%\right.$ purity), silver nitrate $\left(\mathrm{AgNO}_{3}, 98 \%\right.$ purity), potassium ferricyanide $\left(\mathrm{K}_{3} \mathrm{Fe}(\mathrm{CN})_{6}, 99 \%\right.$ purity), copper(II) sulfate (CuSO $4 \cdot 5 \mathrm{H}_{2} \mathrm{O}, 99 \%$ purity), and agar, all from Merck, $\mathrm{KGaA}$, Darmstadt, deionized water, platinum sheet (Pt, $99.9 \%$ purity, $0.5 \mathrm{~mm}$ thick) were used.

\subsection{TDNA synthesis and characterization}

The Ti sheet was cut into small pieces of the size $2.5 \times 1$ $\mathrm{cm}^{2}$ and used for electrochemical anodization and TDNA formation. For this purpose, the Ti sheet was first polished [20] and then rinsed with acetone, alcohol and deionized water for three 15 min-subsequent time periods in an ultrasonic bath and then left in air for drying. In the next step, the Ti sheet was etched chemically by immersion into a solution of $\left(\mathrm{HF} / \mathrm{HNO}_{3} / \mathrm{H}_{2} \mathrm{O}\right)$ with a volume ratio (1:4:5) for $30 \mathrm{~s}$ and then washed with deionized water and dried in air [10]. Electrochemical anodization was done in two steps. The first step was done at $60 \mathrm{~V}$ for $30 \mathrm{~min}$ in $100 \mathrm{ml}$ electrolyte solution of $0.1 \mathrm{M}$ ammonium fluoride containing $98 \mathrm{ml}$ of ethylene glycol (EG) and $2 \mathrm{ml}$ of deionized water [12]. The anode was a Ti sheet, and the cathode was a Pt sheet of the same dimensions $\left(2.5 \times 1 \mathrm{~cm}^{2}\right)$ placed at a distance of $3 \mathrm{~cm}$ from each other in the electrolyte solution with an equal active surface area of $2 \times 1 \mathrm{~cm}^{2}$.

After the first step of electrochemical anodization, the synthesized TDNA was washed with deionized water and then ultrasonicated in ethanol bath for $5 \mathrm{~min}$ to remove the nano-tubes on the surface. After that, the sheet was washed again with deionized water, and the second step of anodization was performed in the same electrolyte solution for $15 \mathrm{~min}$ [10]. The prepared TDNA was washed again with deionized water and dried in air before doping.

The morphology of the synthesized TDNA was investigated using images of scanning electron microscopy 
(SEM). For this, a MIRA3 TESCAN SEM in SE mode and with an accelerating voltage of $30 \mathrm{kV}$ was used. XRD analysis ( $35 \mathrm{kV}, 20 \mathrm{~mA}$, Cu-Ka radiation) was performed for phase analysis of the synthesized TDNA and for anatase phase confirmation. For this test, a sample of $0.5 \times 0.5 \mathrm{~cm}$ was exposed to bombarding $X$-rays and a diffraction pattern was obtained. Comparing it with standard diffraction patterns, the crystalline phase of the sample was identified. The XRD test in this research was conducted by " $X$ ' Pert Pro" from "Panalytical" company.

\subsection{Doping TDNA with $\mathrm{Ag}$, $\mathrm{Fe}$, and $\mathrm{Cu}$}

Before doping, the prepared TDNA was soaked in a $0.1 \mathrm{M}$ sulfuric acid solution for 90 min to remove any probable impurity. Then, silver doping was performed by soaking the TDNA in a water/ethanol solution (4:1) containing $0.05 \mathrm{M}$ silver nitrate at $70^{\circ} \mathrm{C}$ for different time periods of $1,3,5,7$ and $9 \mathrm{~h}[10,13]$. Afterwards, the doped TDNA was washed with deionized water and dried in ambient air [15]. In the next step, the TDNA was calcined at $450^{\circ} \mathrm{C}$ for $2 \mathrm{~h}$ with a heating rate of $2^{\circ} \mathrm{C} / \mathrm{min}$ [18]. Exactly the same procedure with the same concentrations, temperatures and times were applied to TDNA to dope it with Fe and $\mathrm{Cu}$ using potassium ferricyanide and copper (II) sulfate, except doping time that were 1,3 , and $5 \mathrm{~h}$. The resulting doped TDNAs were displayed with X/TDNAn, in which $X$ and $n$ represent the doped element and the doping time, respectively.

\subsection{Photoelectrochemical activity test}

Figure 1 shows a simple demonstration of the laboratory photoelectrochemical equipment used for water splitting. As seen, it consists of two half-cells and a salt bridge and a power supply for applying bias voltage. TDNA and Pt pieces with active areas of $2 \times 1 \mathrm{~cm}^{2}$ were used as anode and cathode, respectively and the distance between the UV light source $(160 \mathrm{~W}$ mercury NARVA lamp) and the TDNA was adjusted for a luminous intensity of $100 \mathrm{~mW} / \mathrm{cm}^{2}$ on TDNA surface [21]. For collecting and measuring the amounts of hydrogen and oxygen gases produced, two graduated cylinders were used upside down as seen in Fig. 1.

The bias voltage was obtained by multiplying the $\mathrm{pH}$ difference of the half-cell electrolytes by a constant value of 0.059 that is equivalent to $(13.15-1.2) 0.059=0.7 \mathrm{~V}$ and adding an optimum value of $1.4 \mathrm{~V}$, which yields a value of 2.1 $\mathrm{V}$ in accordance with Monforth et al. [21].

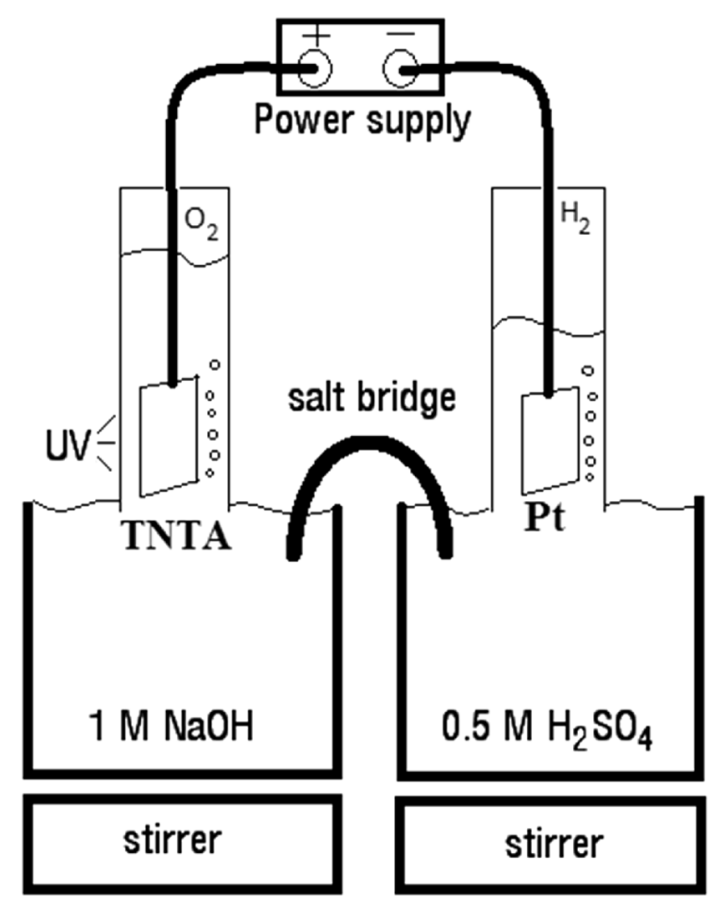

Fig. 1 Schematic of the laboratory equipment used for photoelectrochemical water splitting

\section{Results and discussion}

In this section, we firstly discuss the results of SEM and XRD characterization analyses performed on TDNA and then after representing and comparing the results of photoelectrochemical water splitting and the amounts of hydrogen and oxygen gases produced, the stability of the most effective and the optimally doped TDNA over time will be discussed.

\subsection{TDNA characterization}

Figure 2 shows a number of typical SEM images from the top surface and cross section of the two-step anodized TDNA at different magnifications. According to images represented in Fig. 2, which are prepared at different magnifications, the synthesized TDNA exhibits a relatively uniform top surface consisting of closely packed nano-tubes with internal diameters ranging from $40 \mathrm{~nm}$ to about $75 \mathrm{~nm}$. The SEM image from the cross section of TDNA, shown in Fig. $2 d$, represents the nano-tubes with the length and the wall thickness, estimated to be in the ranges 7 to $8 \mu \mathrm{m}$ and 28 to $55 \mathrm{~nm}$, respectively.

Table 1 compares the geometric dimensions of TDNA synthesized by other researchers using two-step anodization technique, as well as the conditions applied in each of the two steps. A comparison of these data helps in determining the effect of anodizing parameters on 

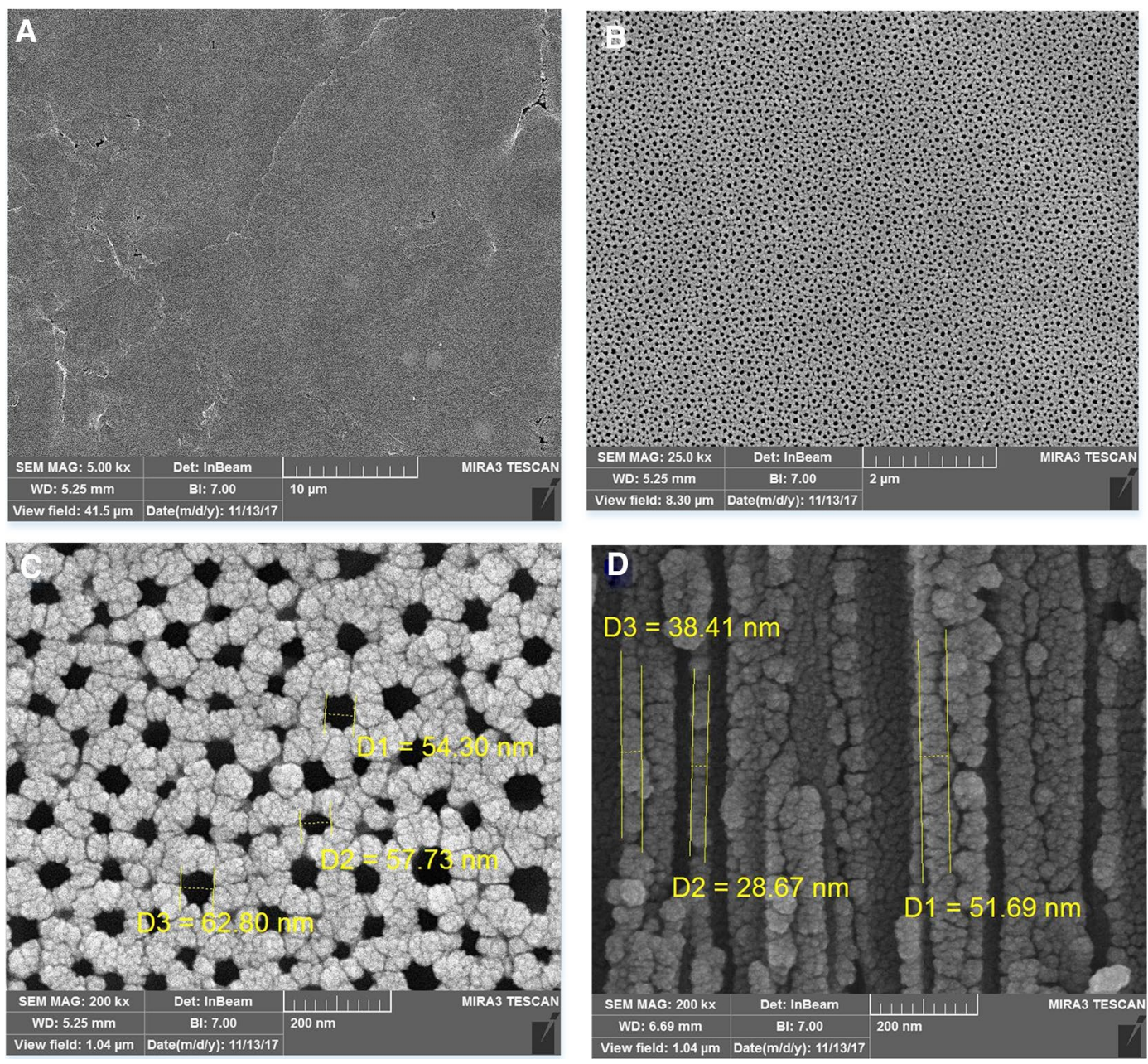

Fig. 2 Typical SEM images of: a, b, c top surface of titanium dioxide nano-tube array at different magnifications of 5000x, 25,000x, $200,000 \times$; $\mathbf{d}$ cross section of titanium dioxide nano-tube array at a magnification of $200,000 \times$

the geometric dimensions of the TDNA. As see in Table 1, the diameter and the length of nano-tubes are strongly affected by the applied anodizing voltage and time and they increase, while higher anodizing voltage and time are applied. Recent research has shown that the photocatalytic property of the TDNA is also enhanced by enlarging the diameter and the length of the nano-tubes [17]. This means that enhanced photocatalytic properties can be achieved by simple adjusting the anodizing parameters and controlling the TDNA geometric dimensions. Compared to these data, the TDNA synthesized in this study is a relatively thick-walled TDNA with almost average sizes in diameter and length.

Before calcination, TDNA exhibits an amorphous structure [24] and calcination at a suitable temperature is required to achieve the photocatalytic active phase of anatase. Figure 3 shows the $\mathrm{X}$-ray diffraction pattern of TDNA after calcination at $450^{\circ} \mathrm{C}$ for $2 \mathrm{~h}$. As seen, calcination operation has transformed the amorphous titanium dioxide into the desired phase of anatase and this is in agreement with the works of Tipparach et al. [25] and Li et al. [26]. The diffraction pattern of the calcined TDNA shows peaks at $2 \theta=25.37^{\circ}, 37.90^{\circ}, 48.16^{\circ}, 54.05^{\circ}, 55.20^{\circ}$, $62.87^{\circ}, 68.98^{\circ}, 75.28^{\circ}$ that are consistent with standard XRD pattern of anatase (JCPDS: 21-1272).

\subsection{Ag-doped TDNA performance}

Figures 4 and 5 show the amounts of hydrogen and oxygen gases evolved by photoelectrochemical water splitting using non-doped TDNA and Ag-doped TDNAs over a time period of $5 \mathrm{~h}$, respectively. As seen in Fig. 4 and compared to TDNA, the three Ag/TDNAs including Ag/TDNA1, $\mathrm{Ag} / \mathrm{TDNA} 2$, and Ag/TDNA3 exhibited stronger photocatalytic properties resulting in higher amount of hydrogen evolution by about $6.8 \%, 16.5 \%$, and $28.0 \%$, respectively. The optimum doping time for Ag using a 0.05 molar silver nitrate solution, therefore, is $5 \mathrm{~h}$ that increased the amount

\section{SN Applied Sciences}


Table 1 Geometric dimensions of titanium dioxide nano-tube arrays synthesized by other researchers

\begin{tabular}{|c|c|c|c|c|c|c|c|c|}
\hline References & [9] & [22] & [11] & [10] & [23] & [12] & [24] & [16] \\
\hline $\begin{array}{l}\text { Inner diameter } \\
\text { of the nano- } \\
\text { tubes }(\mathrm{nm})\end{array}$ & 90 & 50 & $90-140$ & 90 & 80 & 43 & $50-100$ & 100 \\
\hline $\begin{array}{l}\text { Outer diam- } \\
\text { eter of the } \\
\text { nano-tubes } \\
(\mathrm{nm})\end{array}$ & - & - & $120-170$ & - & 120 & - & $80-200$ & - \\
\hline $\begin{array}{l}\text { Wall thickness } \\
\text { of the nano- } \\
\text { tubes (nm) }\end{array}$ & 16 & 10 & $20-50$ & - & - & 11 & - & - \\
\hline $\begin{array}{l}\text { Length of } \\
\text { nano-tubes } \\
(\mathrm{nm})\end{array}$ & 380 & 920 & 24,000 & 9000 & $6000-7000$ & 2400 & - & 50,000 \\
\hline $\begin{array}{c}\text { The first step } \\
\text { anodizing } \\
\text { electrolyte }\end{array}$ & $\begin{array}{l}0.5 \mathrm{wt} \% \mathrm{HF} \\
\text { in } \mathrm{EG}\end{array}$ & $\begin{array}{l}1 \mathrm{M} \mathrm{H}_{2} \mathrm{O} \\
0.1 \mathrm{M} \mathrm{NH}_{4} \mathrm{~F} \\
\quad \text { in EG }\end{array}$ & $\begin{array}{l}\mathrm{EG}=98 \mathrm{ml} \\
0.1 \mathrm{M} \mathrm{NH}_{4} \mathrm{~F} \\
\mathrm{H}_{2} \mathrm{O}=2 \mathrm{ml}\end{array}$ & $\begin{array}{l}\mathrm{EG}=198 \mathrm{ml} \\
0.3 \mathrm{wt} \% \mathrm{NH}_{4} \mathrm{~F} \\
\mathrm{H}_{2} \mathrm{O}=4 \mathrm{ml}\end{array}$ & $\begin{array}{l}3 \text { wt } \% \mathrm{H}_{2} \mathrm{O} \\
0.15 \mathrm{M} \mathrm{NH}_{4} \mathrm{~F} \\
\quad \text { in } \mathrm{EG}\end{array}$ & $\begin{array}{l}2 \text { vol\% } \mathrm{H}_{2} \mathrm{O} \\
0.5 \mathrm{wt} \% \mathrm{NH}_{4} \mathrm{~F} \\
\quad \text { in } \mathrm{EG}\end{array}$ & $\begin{array}{l}2 \text { vol\% } \mathrm{H}_{2} \mathrm{O} \\
0.3 \mathrm{wt} \% \mathrm{NH}_{4} \mathrm{~F} \\
\quad \text { in } \mathrm{EG}\end{array}$ & $\begin{array}{l}0.3 \%(\mathrm{w} / \mathrm{v}) \\
\mathrm{NH}_{4} \mathrm{~F} \\
3 \%(\mathrm{v} / \mathrm{v}) \mathrm{H}_{2} \mathrm{O} \\
\text { in } \mathrm{EG}\end{array}$ \\
\hline $\begin{array}{l}\text { The first step } \\
\text { anodizing } \\
\text { voltage }\end{array}$ & $20 \mathrm{~V}$ & $35 \mathrm{~V}$ & $60 \mathrm{~V}$ & $50 \mathrm{~V}$ & $60 \mathrm{~V}$ & $60 \mathrm{~V}$ & $50 \mathrm{~V}$ & $80 \mathrm{~V}$ \\
\hline $\begin{array}{l}\text { The first step } \\
\text { anodizing } \\
\text { time }\end{array}$ & $0.5 \mathrm{~h}$ & $2 \mathrm{~h}$ & $6 \mathrm{~h}$ & $2 \mathrm{~h}$ & $15 \mathrm{~min}$ & $1.5 \mathrm{~h}$ & $2,4,6 \mathrm{~h}$ & $2 \mathrm{~h}$ \\
\hline $\begin{array}{l}\text { The sec- } \\
\text { ond step } \\
\text { anodizing } \\
\text { electrolyte }\end{array}$ & - & $\begin{array}{l}8 \text { Molar } \mathrm{H}_{2} \mathrm{O} \\
0.2 \text { Molar HF } \\
\text { in EG }\end{array}$ & - & $\begin{array}{l}\mathrm{EG}=198 \mathrm{ml} \\
0.3 \mathrm{wt} \% \mathrm{NH}_{4} \mathrm{~F} \\
\mathrm{H}_{2} \mathrm{O}=4 \mathrm{ml}\end{array}$ & - & $\begin{array}{l}2 \text { vol\% } \mathrm{H}_{2} \mathrm{O} \\
0.5 \mathrm{wt} \% \mathrm{NH}_{4} \mathrm{~F} \\
\quad \text { in } \mathrm{EG}\end{array}$ & - & $\begin{array}{l}0.3 \%(w / v) \\
\mathrm{NH}_{4} \mathrm{~F} \\
3 \%(\mathrm{v} / \mathrm{v}) \mathrm{H}_{2} \mathrm{O} \\
\text { in } \mathrm{EG}\end{array}$ \\
\hline $\begin{array}{l}\text { The second } \\
\text { step anodiz- } \\
\text { ing voltage }\end{array}$ & - & $50 \mathrm{~V}$ & - & $50 \mathrm{~V}$ & - & $30 \mathrm{~V}$ & - & $80 \mathrm{~V}$ \\
\hline $\begin{array}{l}\text { The second } \\
\text { step anodiz- } \\
\text { ing time }\end{array}$ & & $43 \mathrm{~min}$ & & $0.5 \mathrm{~h}$ & & $0.5 \mathrm{~h}$ & & $1 \mathrm{~h}$ \\
\hline
\end{tabular}

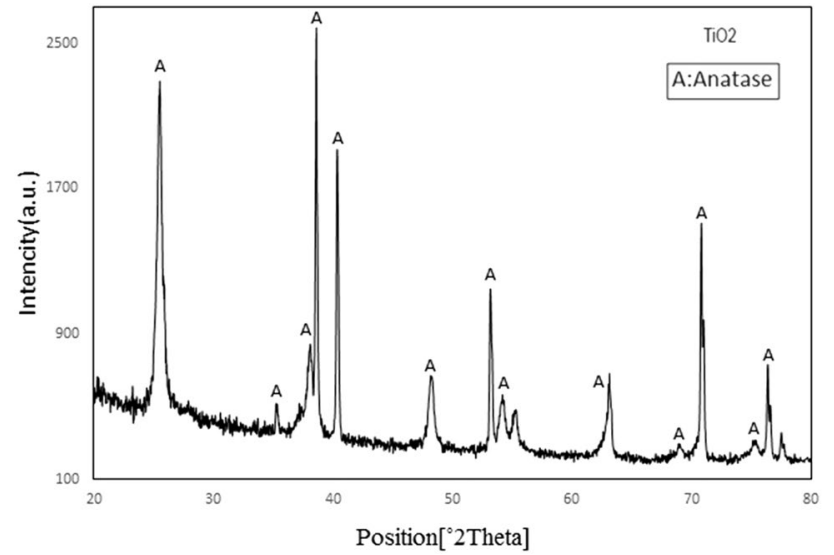

Fig. 3 X-ray diffraction pattern of titanium dioxide nano-tube array after calcination

of hydrogen evolution from $7.38 \mathrm{mmol}$ for non-doped TDNA to $9.45 \mathrm{mmol}$ for Ag/TDNA5 showing $28.0 \%$ increase. Longer doping times weakened the photocatalytic

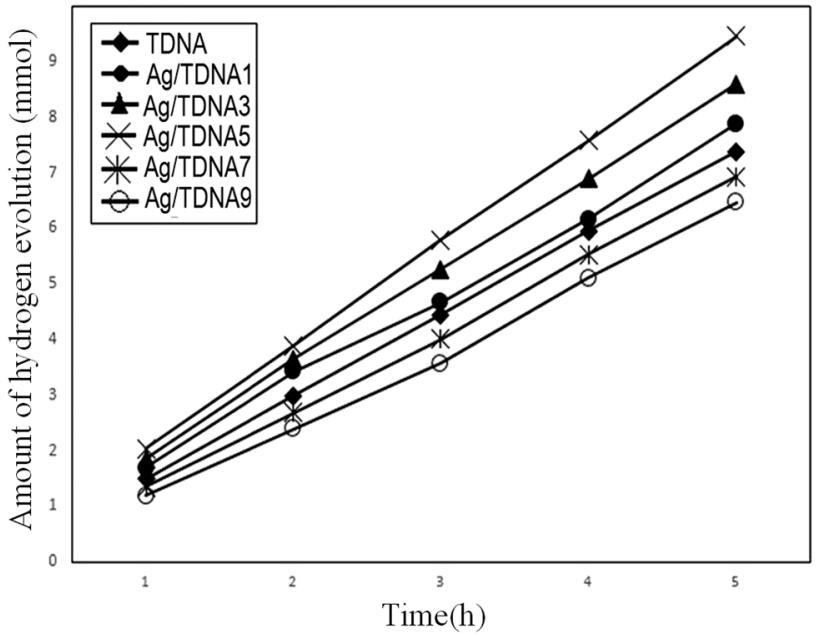

Fig. 4 Amount of hydrogen evolved by photoelectrochemical water splitting using TDNA and Ag-doped TDNAs (active surface area: $2 \mathrm{~cm}^{2}$ ) 


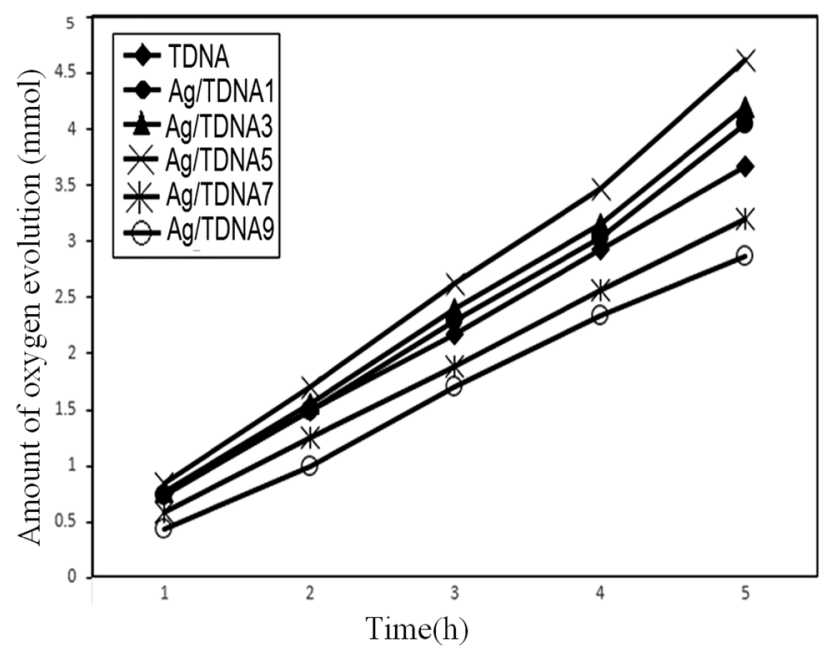

Fig. 5 Amount of oxygen evolved by photoelectrochemical water splitting using TDNA and Ag-doped TDNAs (active surface area: 2 $\mathrm{cm}^{2}$ )

property of TDNA and resulted in lower amounts of hydrogen gas evolution. Oxygen evolution, shown in Fig. 5, also represented a similar trend with higher oxygen gas evolution by about $26 \%$ for Ag/TDNA5 (4.62 mmol) compared to non-doped TDNA (3.66 mmol). Considering the stoichiometry of hydrogen and oxygen elements in water, the amount of oxygen gas evolved should be exactly half of the amount of hydrogen gas evolved. The relatively small deviation between the amounts of hydrogen $(9.45 \mathrm{mmol})$ and oxygen ( $4.62 \mathrm{mmol}$ ) evolution from the stoichiometry ratio is due to errors in reading the gas volumes and converting them into gas amounts in $\mathrm{mmol}$ assuming ideal gas behavior and using ideal gas law.

In an attempt by Lian et al. [12], a TDNA acquired via anodizing method was doped with silver nano-particles by applying pulse electrodeposition method. The doped TDNA showed $40 \%$ increase in photoelectrochemical water splitting when tested under a bias voltage of $0.7 \mathrm{~V}$ with a 300-W Xenon lamp at a distance of $10 \mathrm{~cm}$.

\subsection{Fe-doped TDNA performance}

Figures 6 and 7 compare the performance of Fe-doped TDNAs and non-doped TDNA in evolving hydrogen and oxygen gases through photoelectrochemical water splitting over a time period of $5 \mathrm{~h}$, respectively. As seen in Fig. 6, Fe/TDNA3 exhibited the best performance by evolving $18.50 \mathrm{mmol}$ hydrogen, which shows about $150 \%$ increase compared to non-doped TDNA that evolved $7.38 \mathrm{mmol}$ hydrogen. Fe/TDNA5 resulted in a significantly smaller amount of hydrogen gas evolution $(13.06 \mathrm{mmol})$ compared to Fe/TDNA3. As seen in Fig. 7, oxygen evolution represented a similar trend. Fe/TDNA3 evolved $7.77 \mathrm{mmol}$

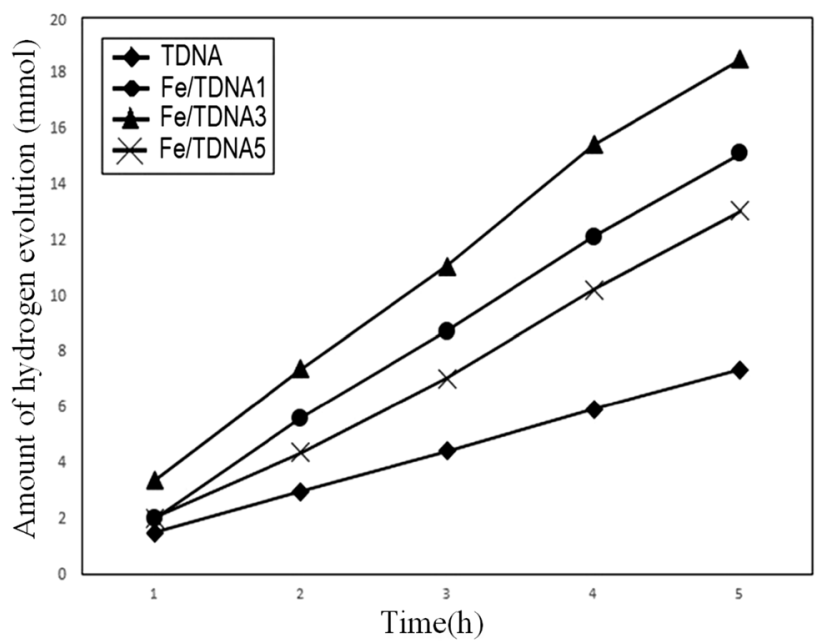

Fig. 6 Amount of hydrogen evolved by photoelectrochemical water splitting using TDNA and Fe-doped TDNAs (active surface area: $2 \mathrm{~cm}^{2}$ )

oxygen gas that shows $112 \%$ increase compared to nondoped TDNA that evolved $3.66 \mathrm{mmol}$ hydrogen. The difference in the percentages of increase in hydrogen and oxygen gas evolutions for Fe/TDNA3 compared to nondoped TDNA is due to errors in measuring the gas volumes and converting them into mmol assuming ideal gas behavior. In a similar study [22], a TDNA doped with an iron (III) oxide $\left(\mathrm{Fe}_{2} \mathrm{O}_{3}\right)$ through $\mathrm{CBD}$ exhibited $50 \%$ increase in photoelectrochemical water splitting compared to control TDNA when tested with a $400 \mathrm{~W}$ mercury lamp. The significantly high difference in enhancing photoelectrochemical water splitting between this study and the present study can be attributed to many influencing factors

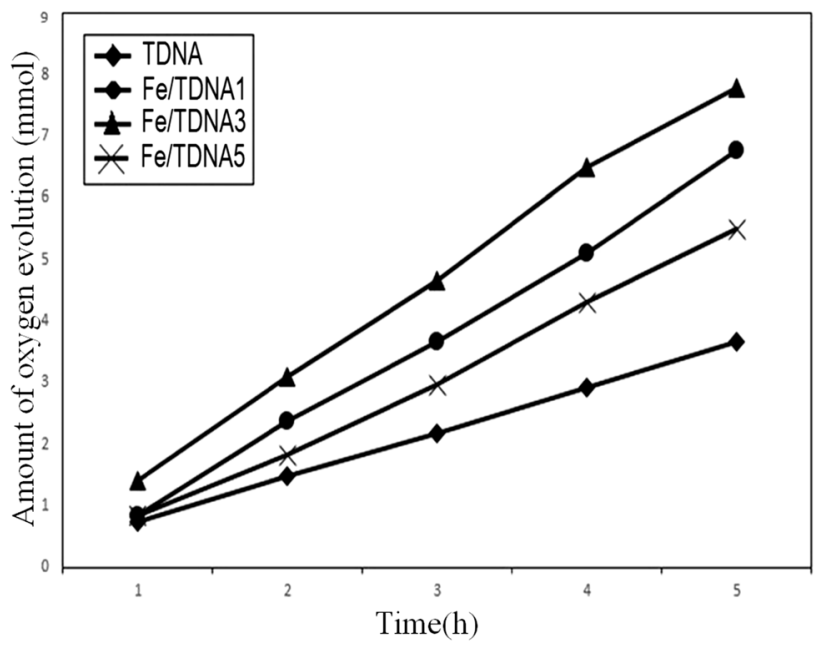

Fig. 7 Amount of oxygen evolved by photoelectrochemical water splitting using TDNA and Fe-doped TDNAs (active surface area: 2 $\mathrm{cm}^{2}$ ) 
including the geometry of the TDNA, the type of doping material, the conditions of doping, the intensity of the UV light impinging on the TDNA surface, and the bias voltage applied. In another study [13], an array of titanium tungstate nano-tubes was prepared by anodizing $T i$ sheet with a solution of dimethyl sulfoxide, hydrogen fluoride and sodium tungstate and doped with Fe via the CBD method. In this study, the array of titanium tungstate nano-tubes was able to enhance the photoelectrochemical water splitting by 2 times ( $100 \%$ increase) with the aid of a $200 \mathrm{~W}$ Xenon lamp, located at a distance for a light intensity of $100 \mathrm{~mW} / \mathrm{cm}^{2}$ on the photocatalyst surface.

\subsection{Cu-doped TDNA performance}

The performance of $\mathrm{Cu}$-doped TDNAs and non-doped one in evolving hydrogen and oxygen gases through photoelectrochemical water splitting over a time period of $5 \mathrm{~h}$ is shown in Figs. 8 and 9, respectively. As Fig. 8 displays, the highest amount of hydrogen evolution is $21.65 \mathrm{mmol}$ that belongs to CU/TDNA1 and is 193\% higher than the amount evolved by non-doped TDNA (7.38 mmol). Similarly, as seen in Fig. 9, Cu/TDNA1 evolved a value of $9.09 \mathrm{mmol}$ oxygen that is $148 \%$ higher than the amount evolved by non-doped TDNA (3.66 mmol). Cu/TDNA3 and Cu/TDNA5 evolved significantly lower amounts of hydrogen and oxygen gases compared to $\mathrm{Cu}$ /TDNA1.

In another study, $\mathrm{Cu}(\mathrm{OH})_{2}$ nano-particles were doped onto a calcined TDNA using CBD technique. Compared to control TDNA, the doped TDNA was able to increase the photoelectrochemical water splitting by almost 20 times with a 300-W Xenon lamp at a distance of $10 \mathrm{~cm}$ [23]. These results show doping with copper and it's compounds

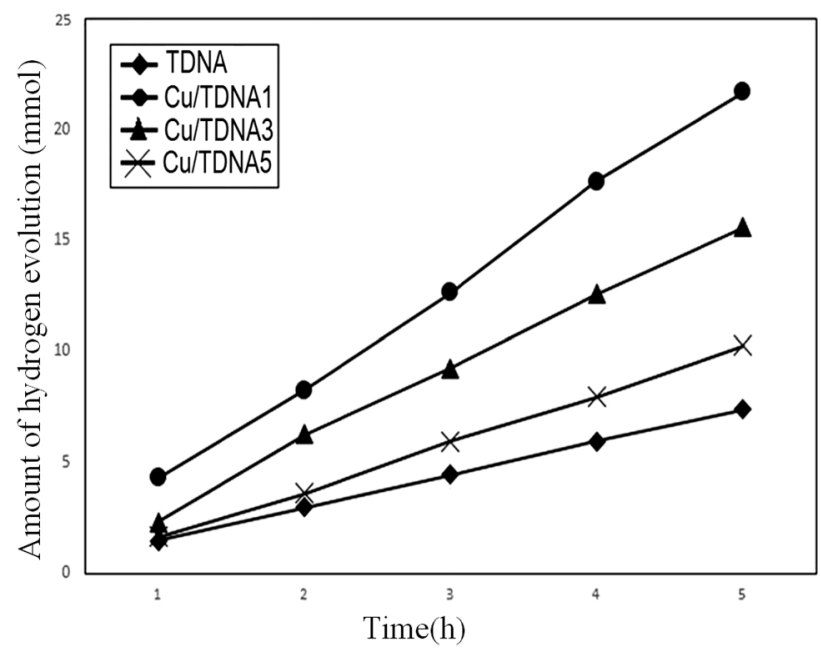

Fig. 8 Amount of hydrogen evolved by photoelectrochemical water splitting using TDNA and Cu-doped TDNAs (active surface area: $2 \mathrm{~cm}^{2}$

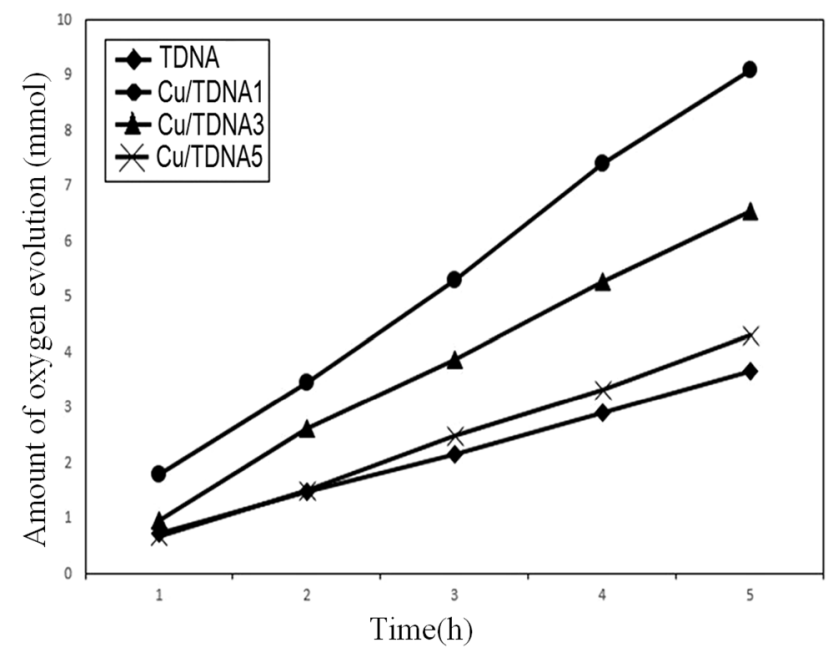

Fig. 9 Amount of oxygen evolved by photoelectrochemical water splitting using TDNA and Fe-doped TDNAs (active surface area: 2 $\left.\mathrm{cm}^{2}\right)$

for enhancing photocatalytic property of TDNA is much more effective compared to many other elements and compounds, and also compared to the relatively limited effects that can be brought about by all the other influencing factors including TDNA geometry, CBD conditions, UV light intensity, bias voltage, etc. The mechanism by which copper doping result in drastically enhanced photocatalytic activity of anatase phase of titanium dioxide is still uncertain. Assadi and Hanaor [27] used density functional theory to simulate surface units of copper-doped (101) planes of anatase to understand the mechanism by which copper doping enhances the photoactivity of anatase surface in aqueous media. Their results suggest that the mechanism is more probably through electronic effects including band-gap narrowing and extension of surface electron-hole lifespan rather than the surface chemistry modifications brought about by adsorbed water.

\subsection{Stability of Cu-doped TDNA}

Stability of photocatalytic property is very important because it determines the lifetime of the photocatalyst in practical and industrial applications. In order to evaluate the stability of $\mathrm{Cu} / \mathrm{TDNA} 1$, as the most effective photocatalyst selected in this study, five consecutive runs of photoelectrochemical water splitting were performed using a newly prepared $\mathrm{Cu}$ /TDNA 1 . Table 2 , shows the amount of hydrogen evolution in these five consecutive runs. As seen, the amount of hydrogen evolution remained the same in every of the five runs. These results indicate that the stability of $\mathrm{Cu} / \mathrm{TDNA} 1$ is relatively high and can retain its photocatalytic property in a significant period of time. Other researchers also reported a good stability for 
Table 2 Stability of $\mathrm{Cu} / \mathrm{TDNA} 1$ for up to five consecutive cycle of hydrogen evolution through photoelectrochemical water splitting

\begin{tabular}{llllll}
\hline No. of run & 1 & 2 & 3 & 4 & 5 \\
\hline Total amount of hydrogen evolved $(\mathrm{mmol})$ & 21.660 & 21.653 & 21.648 & 21.646 \\
\hline
\end{tabular}

photocatalytic properties of TDNAs doped with zinc oxide $(\mathrm{ZnO})$ and chromium metal by repeating consecutive runs of photoelectrochemical water splitting [10]. Similar results confirm a relatively good stability for photocatalytic properties of TDNA.

\subsection{Performance comparison}

Compared to non-doped TDNA, Ag/TDNA5 and Fe/TDNA3 with doping times of 5 and $3 \mathrm{~h}$, respectively, increased the amount of hydrogen evolution by about $28.0 \%$ and $150 \%$. Cu/TDNA1, however, showed significantly better performance by evolving the highest amount of hydrogen, i.e. $21.65 \mathrm{mmol}$, which is $193 \%$ higher than the amount hydrogen $(7.38 \mathrm{mmol})$ evolved by non-doped TDNA. Therefore, TDNA doped with copper (II) sulfate performs better by increasing the amount of hydrogen evolution by up to three times in a 5-h photoelectrochemical water splitting operation.

\section{Conclusion}

In this research, a titanium dioxide nano-tube array (TDNA) was synthesized by a two-step electrochemical anodizing method using a proportioned solution of ammonium fluoride, ethylene glycol, and deionized water. The TDNA was then calcined to achieve anatase crystalline phase, and after characterization, it was doped individually with three different $0.05 \mathrm{M}$ solutions of silver nitrate, potassium ferricyanide and copper (II) sulfate at different time intervals by CBD method to enhance its photocatalytic properties for photoelectrochemical water splitting. The optimum doping time for silver nitrate, potassium ferricyanide and copper (II) sulfate solutions were 5,3 , and $1 \mathrm{~h}$, resulting in increased hydrogen evolution amounts by $28 \%, 150 \%$, and $193 \%$, respectively, in a 5 -h photoelectrochemical water splitting operation compared to control non-doped TDNA. The results confirm that compared to control non-doped TDNA, the TDNA doped with copper (II) sulfate increases the amount of hydrogen evolution by up to three times producing as much as $21.65 \mathrm{mmol}$ after $5 \mathrm{~h}$ of photoelectrochemical water splitting. Also, the results show TDNA doped with copper (II) sulfate solution for $1 \mathrm{~h}$ does not show any reduction in its photocatalytic activity after five consecutive 5 -h runs of photoelectrochemical water splitting.

\section{SN Applied Sciences}

\section{Compliance with ethical standards}

Conflict of interest The authors declare that they have no conflict of interest.

\section{References}

1. Gong J, Lai Y, Lin C (2010) Electrochemically multi-anodized $\mathrm{TiO}_{2}$ nanotube arrays for enhancing hydrogen generation by photoelectrocatalytic water splitting. Electrochim Acta 55(16):47764782. https://doi.org/10.1016/j.electacta.2010.03.055

2. Ratnawati, Gunlazuardi J, Dewi EL, Slamet (2014) Effect of $\mathrm{NaBF}_{4}$ addition on the anodic synthesis of $\mathrm{TiO}_{2}$ nanotube arrays photocatalyst for production of hydrogen from glycerol-water solution. Int J Hydrog Energy 39(30):16927-16935 https://doi. org/10.1016/j.ijhydene.2014.07.178

3. Yablonovitch E (1993) Photonic band-gap structures. J Opt Soc Am B 10(2):283-295. https://doi.org/10.1364/JOSAB.10.000283

4. Sheldon J (1964) The preferred valence states of transition metals. Aust J Chem 17(8):833-837. https://doi.org/10.1071/CH964 0833

5. Murphy AB (2007) Band-gap determination from diffuse reflectance measurements of semiconductor films, and application to photoelectrochemical water-splitting. Sol Energy Mater Sol Cells 91(14):1326-1337. https://doi.org/10.1016/j.solmat.2007.05.005

6. Fujishima A, Honda K (1972) Electrochemical photolysis of water at a semiconductor electrode. Nature 238:37. https://doi. org/10.1038/238037a0

7. Gong D, Grimes CA, Varghese $O K, H u$ W, Singh $R$, Chen Z, Dickey EC (2001) Titanium oxide nanotube arrays prepared by anodic oxidation. J Mater Res 16(12):3331-3334. https://doi. org/10.1557/JMR.2001.0457

8. Roy P, Berger S, Schmuki P (2011) $\mathrm{TiO}_{2}$ nanotubes: synthesis and applications. Angew Chem Int Ed Engl 50(13):2904-2939. https ://doi.org/10.1002/anie.201001374

9. Yu J, Gong C, Wu Z, Wu Y, Xiao W, Su Y, Sun L, Lin C (2015) Efficient visible light-induced photoelectrocatalytic hydrogen production using $\mathrm{CdS}$ sensitized $\mathrm{TiO}_{2}$ nanorods on $\mathrm{TiO}_{2}$ nanotube arrays. J Mater Chem A 3(44):22218-22226. https://doi. org/10.1039/c5ta04107d

10. Xiao FX, Hung SF, Miao J, Wang HY, Yang H, Liu B (2015) Metalcluster-decorated $\mathrm{TiO}_{2}$ nanotube arrays: a composite heterostructure toward versatile photocatalytic and photoelectrochemical applications. Small 11(5):554-567. https://doi. org/10.1002/smll.201401919

11. Momeni MM, Ghayeb Y (2015) Fabrication, characterization and photoelectrochemical performance of chromium-sensitized titania nanotubes as efficient photoanodes for solar water splitting. J Solid State Electrochem 20(3):683-689. https://doi. org/10.1007/s10008-015-3093-3

12. Lian Z, Wang W, Xiao S, Li X, Cui Y, Zhang D, Li G, Li H (2015) Plasmonic silver quantum dots coupled with hierarchical $\mathrm{TiO}_{2}$ nanotube arrays photoelectrodes for efficient visible-light photoelectrocatalytic hydrogen evolution. Sci Rep 5:10461. https:// doi.org/10.1038/srep 10461 
13. Chen H, Chen K-F, Lai S-W, Dang Z, Peng Y-P (2015) Photoelectrochemical oxidation of azo dye and generation of hydrogen via $\mathrm{CN}$ co-doped $\mathrm{TiO}_{2}$ nanotube arrays. Sep Purif Technol 146:143153. https://doi.org/10.1016/j.seppur.2015.03.026

14. Chan C-H, Samikkannu P, Wang H-W (2016) $\mathrm{Fe}_{2} \mathrm{O}_{3} / \mathrm{CdS}$ co-sensitized titania nanotube for hydrogen generation from photocatalytic splitting water. Int J Hydrog Energy 41(40):17818-17825. https://doi.org/10.1016/j.ijhydene.2016.08.026

15. Momeni MM, Ghayeb Y, Davarzadeh $\mathrm{M}(2015) \mathrm{WO}_{3}$ nanoparticles anchored on titania nanotube films as efficient photoanodes. Surf Eng 31(4):259-264. https://doi.org/10.1179/1743294414 y. 0000000450

16. Momeni MM, Ghayeb Y (2015) Visible light-driven photoelectrochemical water splitting on $\mathrm{ZnO}-\mathrm{TiO}_{2}$ heterogeneous nanotube photoanodes. J Appl Electrochem 45(6):557-566. https://doi. org/10.1007/s10800-015-0836-x

17. Momeni MM (2016) Highly efficient photoelectrochemical water splitting by a novel nanocomposite titania photoanode. Mater Res Innov 20(4):317-325. https://doi.org/10.1080/14328 917.2016.1138585

18. Natarajan K, Natarajan TS, Kureshy RI, Bajaj HC, Jo WK, Tayade RJ (2015) Photocatalytic $\mathrm{H}_{2}$ Production using semiconductor nanomaterials via water splitting-an overview. Adv Mater Res 1116:130-156. https://doi.org/10.4028/www.scientific.net/ AMR.1116.130

19. Yu J, Wu Z, Gong C, Xiao W, Sun L, Lin C (2016) Fe(3+)-doped $\mathrm{TiO}(2)$ nanotube arrays on Ti-Fe alloys for enhanced photoelectrocatalytic activity. Nanomaterials. https://doi.org/10.3390/ nano6060107

20. Alsawat M, Altalhi T, Gulati K, Santos A, Losic D (2015) Synthesis of carbon nanotube-nanotubular titania composites by catalyst-free CVD process: insights into the formation mechanism and photocatalytic properties. ACS Appl Mater Interfaces 7(51):28361-28368. https://doi.org/10.1021/acsami.5b08956
21. Monfort O, Pop L-C, Sfaelou S, Plecenik T, Roch T, Dracopoulos V, Stathatos E, Plesch G, Lianos P (2016) Photoelectrocatalytic hydrogen production by water splitting using $\mathrm{BiVO}_{4}$ photoanodes. Chem Eng J 286:91-97. https://doi.org/10.1016/j. cej.2015.10.043

22. Chiarello GL, Zuliani A, Ceresoli D, Martinazzo R, Selli E (2016) Exploiting the photonic crystal properties of $\mathrm{TiO}_{2}$ nanotube arrays to enhance photocatalytic hydrogen production. ACS Catal 6(2):1345-1353. https://doi.org/10.1021/acscatal.5b02817

23. Nguyen NT, Altomare M, Yoo JE, Taccardi N, Schmuki P (2016) Noble Metals on anodic $\mathrm{TiO}_{2}$ nanotube mouths: thermal dewetting of minimal Pt Co-catalyst loading leads to significantly enhanced photocatalytic $\mathrm{H}_{2}$ generation. Adv Energy Mater 6(2):1501926. https://doi.org/10.1002/aenm.201501926

24. Samran B, Krongkitsiri P, Pimmongkol S, Budngam S, Tipparach $U$ (2013) Preparation and microstructure of titania $\left(\mathrm{TiO}_{2}\right)$ Nanotube arrays by anodization method. Adv Mater Res 802:104-108. https://doi.org/10.4028/www.scientific.net/AMR.802.104

25. Tipparach U, Wongwanwatthana P, Sompan T, Saipin T, Krongkitsiri $\mathrm{P}$ (2008) Preparation and characterization of nano- $\mathrm{TiO}_{2}$ thin films by sol-gel dip-coating method. CMU J Nat Sci 7(1):129-136

26. Li S, Liu Y, Zhang G, Zhao X, Yin J (2011) The role of the $\mathrm{TiO}_{2}$ nanotube array morphologies in the dye-sensitized solar cells. Thin Solid Films 520(2):689-693. https://doi.org/10.1016/j. tsf.2010.12.250

27. Assadi MHN, Hanaor DAH (2016) The effects of copper doping on photocatalytic activity at (101) planes of anatase $\mathrm{TiO}_{2}$ : a theoretical study. Appl Surf Sci 387:682-689. https://doi. org/10.1016/j.apsusc.2016.06.178

Publisher's Note Springer Nature remains neutral with regard to jurisdictional claims in published maps and institutional affiliations. 